\title{
Influence of fibres on rheological properties and toughness of bituminous binder
}

\begin{abstract}
Many studies have been made to examine different ways to modify bitumen and asphalt mixtures in response to increasing performance requirements. One of these is the use of additive materials and in this study, the potential of cellulose and glass fibres to modify the rheological properties of bitumen has been investigated. To achieve this, mixtures of bitumen with different contents of fibre were prepared and the properties of the bitumen and resulting modified binders were tested (penetration, softening point, viscosity and double edge notch tension test along with rheological testing in the dynamic shear rheometer). The experimental results demonstrated that adding fibres improves the rheological properties of bitumen across a range of loading frequencies and temperatures. Adding fibre reduced the penetration and increased the softening point and viscosity of bitumen implying improved rutting resistance of asphalt mixtures using these mastics. Finally this investigation established that adding fibre to bitumen improved its toughness, which could lead to improvement in asphalt fatigue performance. However, there are some limitations that are also discussed.
\end{abstract}

Keywords: glass fibre, cellulose fibre, fibre reinforced mastic, rheology, compatibility, stiffness, essential work of fracture, toughness.

\section{Introduction}

This study examines the effect of the addition of fibres on some mechanical properties, and rheological properties of bituminous mastic. Fibres can significantly improve bitumen's penetration and viscosity $[1,2]$. Seventy percent of bitumen is used in road construction as the binder mixed with aggregate and filler particles to form asphalt 
mixtures [3]. Bitumen is a viscoelastic material and it is well known that the mechanical behaviour of viscoelastic materials depend on loading time and temperature. The behaviour of bitumen plays a significant role in the performance and service life of flexible pavements.

The binder composed of fibres and bitumen works as the material that bonds an asphalt mixture together and is, therefore, an important part of that mixture. The properties of fibres (length, adhesion, absorption, swelling) and how they affect bitumen is complex. Fibres are added to bitumen to enhance its viscoelastic properties, for instance by improving the bitumen viscosity and stiffness $[4,5]$. Fibres are mainly used in stone matrix asphalt and gap graded mixtures to prevent the draining out of binder during mixing and compaction [6-8]. Fibres can reinforce the asphalt mastic through the three dimensional network they form and also through absorption of the asphalt binder and through adhesion in the mix $[1,5]$. Additionally, fibres have the potential to increase moisture resistance [9], fatigue resistance [10-12] and rutting resistance and creep compliance [13].

In this paper, fibre modified binder mastics were prepared with different fibre types (cellulose, $6 \mathrm{~mm}$ glass and $13 \mathrm{~mm}$ glass fibres). Cellulose fibres are natural fibres obtained most commonly from woody plants. Although glass fibres have desirable properties, such as low thermal expansion coefficient, high tensile modulus, high elastic recovery and high softening point, a literature review shows that their use has not been reported very often [14]. Experiments were conducted to evaluate the viscoelastic characteristics of the base bitumen and modified mastic with various fibre additions. These tests included penetration, softening point, viscosity, dynamic shear rheometer (DSR) and the double edge notch tension (DENT) test. 


\section{Experimental programme}

\subsection{Materials}

The binder used in the experimental programme was a 40/60 penetration grade bitumen[15]. Three fibre types including two types of glass fibre and cellulose fibres were used as the additive to bitumen. Table 1 lists the basic properties of these fibres. Table 2 summarises the experimental programme. Three fibre concentrations of $0.5 \%$, $1.0 \%$ and $2.0 \%$ by bitumen volume were selected. The glass fibres have two different lengths of 13 and $6 \mathrm{~mm}$ and diameter of 12 microns, which are termed glass-I and glass$\mathrm{s}$ respectively. Micrographs of these three fibre types and the fibre reinforced bitumen are given in Figure 1 and Figure 2 respectively, using a scanning electron microscope (SEM). An SEM image of cellulose mastic is not included in this study because these fibres were difficult to identify and did not protrude from the faces of the mastic specimens in the same way as the glass fibre. This may be due to the dimensions and absorbent natural of cellulose fibre.

In Figure 1, compared with the glass fibres, the cellulose fibre is much rougher. The cellulose fibre has a width of about 25 microns with length from 20 to 2,500 microns, with irregular size and uneven surface texture and shows an irregularly shaped surface with interweaved branches. Glass fibres are produced with a uniform cylindrical shape and smooth surface texture. They are made up of bundles of individual fibres. Figure 2 shows the formation of a network of fibres for a glass fibre reinforced mastic.

\subsection{Experimental methods}

Bitumen was placed in an oven at $160^{\circ} \mathrm{C}$ for more than one hour to make it fluid enough for mixing. A specific experimental procedure was used to obtain homogeneous bitumenfibre mastics. A Stuart mixer with a SS10 stirrer was used to apply a specific mixing speed (500 rpm) which prevented air bubbles forming in the bitumen-fibre mastic. Thermocouple probes were used to monitor the temperature throughout mixing by placing the probe directly inside the composite in the mixing vessel. Fibres were slowly 
added to the bitumen, while the mixing continued at constant speed to prevent the fibres from agglomerating. Bitumen-fibre mastics were mixed for one hour at $160^{\circ} \mathrm{C}$ to produce homogeneous composites.

The penetration of the bitumen mixed with different fibres was measured with a STANHOPE-SETA penetrometer[15]. The penetration test was used to evaluate the hardness of the fibre reinforced bitumen mastic. Penetration is defined as the depth of penetration of a standard needle under a one hundred grams load after a five second loading time at a specified temperature and the penetration value expressed in units of $0.1 \mathrm{~mm}$. The fibre reinforced binder samples were left for one hour in air and then placed in a water bath at $25^{\circ} \mathrm{C}$ for one hour to equilibrate thermally before the penetration test.

Softening point (ring and ball) tests were conducted under standardised test conditions to determine the temperature at which a phase change occurs in the bitumen or mastics according to EN 1427 [16].

A standard rotational viscometer (Model LVDV-II+ PRD, Brookfield Engineering Inc.) was used to measure the viscosity of the fibre reinforced bitumen [17].

A Bohlin Gemini 200 (DSR) was used in this study for measuring the rheological properties of base and fibre reinforced bitumen. It has a torque range between 0.5 $(\mu \mathrm{N} \cdot \mathrm{m})$ and $200(\mathrm{mN} \cdot \mathrm{m})$. There is a sensor attached to the shaft to detect the movement of the measuring system [18]. Eleven testing frequencies ranging from 0.1 to $10.0(\mathrm{~Hz})$ were used in DSR tests with nine testing temperatures between 30 and $70^{\circ} \mathrm{C}$ (at increments of $5^{\circ} \mathrm{C}$ ).

For the DENT test, used to measure the total essential and plastic work of fracture, samples were prepared by pouring the binder into moulds with inserts at both ends. A $45^{\circ}$ notch angle was used to facilitate ease of handling during the removal of the specimens from the mould. The test speed was kept constant at $50 \mathrm{~mm} / \mathrm{min}$ and the 
temperature at $15( \pm 0.5)^{\circ} \mathrm{C}$. Six samples were prepared, two for each ligament length of 15,10 and $5 \mathrm{~mm}[19]$.

\section{Results and Discussion}

\subsection{Penetration}

Penetration is a common test used to measure bitumen hardness. The penetration value was taken as the average of three readings. It was found that the penetration value decreases significantly with addition of glass-I and glass-s fibres, and less so with addition of cellulose fibres, as illustrated in Figure 3 (error bars represent standard deviation of the three results). The magnitude of the decrease in penetration is a function of glass fibre content, however, fibre length has a small effect and there is little difference between glass-I and glass-s. Note that cellulose fibres are uneven and shorter than glass fibre and may, therefore, be less able to form a rigid network within the mastic.

\subsection{Softening point (Ring and Ball)}

Softening point has been linked to the permanent deformation of asphalt mixtures. The softening point value increases significantly with the addition of fibres, as shown in Figure 4 (error bars represent the standard deviation of the results). The magnitude of the increase in softening point is a function of fibre content. Glass-I fibre showed the highest increase in softening point of the mastic.

\subsection{Viscosity}

The addition of fibre increased the viscosity of the base bitumen, implying improved rutting resistance for asphalt mixtures using this binder [1]. Figures 5 and 6 show that viscosity increases with the addition of fibres and this became more evident at high temperatures. The figures show the average of three values and error bars which represent the standard deviation. The addition of glass fibres led to a significant increase in viscosity. This effect could be due to the glass fibre surface texture and dimensions 
(length and width) which help to form a network of fibres, interacting to create a continuous network of fibres through the bitumen (see Figure 2). This network of fibres increased the resistance to deformation by reinforcing the bitumen. However, the addition of $0.5 \%$ cellulose fibre exhibited a more limited increase in viscosity, which may be due to cellulose fibres acting only as a dispersed material and not forming a continuous network at low fibre content. The viscosity ratio of fibre mastic to bitumen increases with increasing fibre content and temperature up to $160^{\circ} \mathrm{C}$, which is important to asphalt mixture strength. This is because higher viscosity prevents draindown and at the same time increases the resistance to deformation of an asphalt mixture [1].

Chen and Lin [1] recommended that a stiffening effect (viscosity ratio) of ten times should be suitable to reinforce bitumen in terms of workability. They point out that using high amount of fibre would lead to fibre-fibre interaction. Mixing more fibres than the optimum concentration is not good, because too much reinforcement could lead to brittle mastics. Therefore special attention should be paid when high fibre contents are added, which may result in voids during the mixing process and lead to poor pavement performance [1]. The stiffening effect is achieved for the glass fibres at addition of $0.5 \%$ and $1 \%$ but for the cellulose fibre only at an addition of $1 \%$. The reinforcement effect is not the only factor that should be considered for the desirable content of fibres. It is important to note that other factors should be examined such as cost, workability of the resulting composite and that too much fibre could lead to brittleness. Adding a high fibre percentage to the bitumen may lead to the fibre properties dominating those of the bitumen, leading to a brittle material. Other research showed that increased fibre content led to decreased elongation at rupture [1]. Note that long glass fibres showed a higher increase in viscosity than short ones. However, the effect of glass fibre length is clearer at low fibre content $(0.5 \%)$. 
Improving bitumen viscosity is important to improve asphalt performance especially at high temperature. These mastics are not directly comparable with asphalt specifications and further investigation will be made evaluating the influence of this increase on compaction by investigating the differences in the compaction effort between control and fibre reinforced asphalt mixture, while using the same mixing time and temperature.

\subsection{Master Curves}

\subsubsection{Complex Modulus Master Curves}

The rheological properties, complex modulus and phase angle master curves for fibre mastic can be constructed utilising the time-temperature superposition principle (TTSP) [20]. Figure 7 depicts the complex modulus master curves for the base bitumen and binder containing different fibres at $0.5 \%$ by bitumen volume. The complex modulus for fibre mastics was slightly higher than that of base bitumen across all the range of frequencies and low temperatures $\left(30-45^{\circ} \mathrm{C}\right)$.

At low frequencies and high temperatures $\left(50-70^{\circ} \mathrm{C}\right)$ the modulus value of the mastic containing cellulose fibre, glass-I and glass-s fibre was about 2.6 times, 1.5 times and 1.4 times greater than the value for base bitumen, respectively. This indicates that the stiffening effects of fibre modifiers were of greater magnitude at low frequencies and high temperatures. The slight increase in complex modulus at low concentration may have been due to the fact that small amounts of fibre cannot interact with each other and act only as dispersed materials. It seems possible that these results are due to the viscosity of the base bitumen being low enough at high temperatures to permit the small amount of fibre to influence the stiffness. The conventional tests, such as penetration and high temperature viscosity, are able to demonstrate increases in hardness and viscosity but they are unable to quantify the unique rheological characteristics of different fibre mastics. Constructing complex modulus ( $\left.G^{*}\right)$ master curves for fibre mastic allows ( $\left.\mathrm{G}^{*}\right)$ to be predicted at frequencies and/or temperatures that would be difficult to determine in the laboratory and which represent all possible pavement 
climatic and loading conditions. DSR samples are small compared to penetration and viscosity test samples and this may affected the degree of fibre entanglement in the DSR sample at low fibre content $(0.5 \%)$. This might explain the different influence of fibres on the conventional (e.g. penetration) and properties of mastic measured using the DSR at low fibre content.

The master curves showed a marked influence of fibres on complex modulus for the $1 \%$ and $2 \%$ fibre mastics at low frequencies and high temperatures $\left(50-70^{\circ} \mathrm{C}\right)$ as shown in Figures 8 and 9 . The complex modulus value of bitumen binder containing $1 \%$ cellulose fibre, glass-I and glass-s fibre was about 7, 4 and 2 times greater than the value of the base bitumen at low frequency and high temperatures, respectively. For $2 \%$ cellulose fibre, glass-I and glass-s fibre the values were about 18, 7 and 3.5 times greater than the value of the original binder, respectively. This increase in complex modulus could be due to the fibres forming small networks gradually interacting with each other to form extended networks in the bitumen. This three dimensional network acts as a supporting structure, strengthening the bitumen and reducing deformation (see Figure 2).

It should be noted that the effect of cellulose fibre on complex modulus was greater than that of glass fibre. This result was considered to some extent surprising, because the glass fibre has higher modulus of elasticity, tensile strength and is longer than the cellulose fibre. This may be due to the small size of the DSR sample, which affects the distribution and orientation of glass fibres and which could influence the strength and stiffness of the composites. This behaviour of glass fibre may have been due to unidirectional orientations providing poor properties, especially where the load was perpendicular to the fibres, leading to lower stiffness. This effect may not be so marked for the shorter cellulose fibres. In addition, short, randomly oriented fibres having a small aspect ratio are easily introduced into the matrix and give relatively isotropic behaviour in the composite [21]. It is important to note however, that this possible effect of fibre length is not appeared for the shorter glass fibre compared to the longer but both are much longer than the cellulose fibres. The rough surface texture and 
absorption properties of the cellulose fibre may have also affected the complex modulus result.

\subsubsection{Phase Angle Master Curves}

Phase angle is an indicator of the viscoelastic properties of bitumen binder. A $0^{\circ}$ phase angle represents a purely elastic material, while $90^{\circ}$ represents a purely viscous material [22]. Time temperature superposition may give an indication about the compatibility of the fibre mastic systems. This is characterised by smooth complex modulus master curves and the difference in the plots of phase angle master curves between fibre mastic and base binder. While, the complex modulus master curves of all mastics followed a similar pattern, the phase angle master curves varied. The results can be seen in figures 10-12.

It is interesting to note that the phase angles decreased significantly when fibres were added, indicating that adding fibres led to improved elastic properties of asphalt binders, mainly at high temperatures and low frequency levels. For instance, in the case of mastic with $1.0 \%$ cellulose, glass-I and glass-s fibres, the phase angles were reduced by about $28^{\circ}, 13^{\circ}$ and $4^{\circ}$ respectively. The reduction of phase angle results in the improvement of the resistance to permanent deformation for the bituminous binders because lower phase angle indicates more elastic behaviour than viscous behaviour [23, 24].

Three distinct patterns can be determined to identify their plateau zones. The phase angle of the base binder decreases with increase in frequency for all test temperatures. The phase angle master curve of the glass fibre mastics showed an increase in phase angle with the increase of frequency at high temperatures $\left(55^{\circ}-70^{\circ} \mathrm{C}\right)$ and high fibre content. The phase angle master curve of the cellulose fibre mastics showed a peak at intermediate temperatures, followed by a drop toward lower frequencies (high temperatures) and there was a noticeable decrease in phase angle at lower frequencies (high temperature range). Cellulose fibres led to a significant decrease in the phase angle compared to the base bitumen at low frequencies for all additions. This decrease in 
phase angle implies a significant improvement in bitumen elastic properties. The reason for the significant decrease in the phase angle may have been swelling of the cellulose fibres due to absorption of bitumen and the interaction of the fibres to form a continuous network within a highly modified binder ( $2 \%$ addition) $[1,23]$. This is consistent with the fact that cellulose fibre has high absorption value for water (although this has not been measured for bitumen) and swelling of the fibre due to absorption of bitumen might increase as the temperature increases, within a highly modified binder. Cellulose fibres are usually used in stone matrix and open graded asphalt mixtures to prevent draindown of the binder, which has been attributed in part to its higher absorption of the bituminous light fraction compared with other fibres [25]. This may also depend on the compatibility between the bitumen and the fibre used. For instance, polymers have good compatibility with a high aromatic content bitumen [26, 27]. Previous research has suggested that the occurrence of a plateau in the phase angle curves indicates a higher interaction level between the modifier and bitumen [28]. In this study the cellulose fibre mastics showed a different behaviour to the glass fibre mastics and base bitumen by forming such a plateau zone. This may indicate that cellulose fibre is more compatible with bitumen than glass fibre. Moreover, the surface texture of cellulose fibres as shown in the scanning electron microscope (SEM) consists of small bundles with a rough surface. This texture may help cellulose fibres to establish a greater network effect than the long and smooth surface texture of glass fibres inside the small DSR sample. Polymer modification of bitumen also leads to changes in phase angle master curves [29] and this has been associated with the changes in chemical composition of bitumen due to chemical reaction or absorption of bitumen fractions [30, 31]. Absorption of some fraction of the bitumen by cellulose fibres may, therefore, also lead to changes in the master curves. However, further investigation is needed to explore the distribution and effect of fibre in the modified asphalt mastic and in asphalt mixtures. 


\subsubsection{Rutting parameters}

The influence of frequency and temperature on the rutting parameter $\left(\mathrm{G}^{*} / \sin \delta\right)$ is illustrated in Figures 13 through 15. The rutting parameter (G*/sin $\delta)$ is considered as an indicator for evaluating the resistance to permanent deformation of both pure and fibre modified binder $[2,23,32]$. It was observed that the addition of fibre resulted in the improvement of bitumen binder's high temperature stability. The results indicate that the value of $\mathrm{G}^{*} / \sin \delta$ using cellulose fibre was the highest followed by glass-I fibre then glass$\mathrm{s}$ fibre and finally pure bitumen for $1 \%$ and $2 \%$ addition of fibres. The value of rutting parameter increased with an increase in fibre percentage and decreased with an increase in test temperature. Therefore, the bituminous binder is characterised by obvious temperature sensitivity. This means fibres could improve permanent deformation resistance of asphalt mixtures especially at high temperatures, where rutting is more likely to be a significant problem for asphalt mixture performance.

\subsection{Double edge notched tension (DENT) test}

The DSR results may indicate that the compatibility of fibre reinforced bitumen mastics is good. Compatibility is a complicated phenomenon due to the complex nature of bitumen. According to a past study the degree to which a modifier enhances the bitumen's properties depends on the compatibility of the modifier and the bitumen. For instance, bitumen rheological and thermal properties will improve more with highly compatible polymers [33]. The formation of a plateau in the phase angle master curves shows a higher interaction level between the modifier and bitumen[28]. Together with real fracture evaluation, this can give more detailed predictions of long-term performance. However, the linear viscoelastic region parameters are less likely to be correlated to high strain region parameters like ductile failure and brittle fracture [34]. The following investigation provides more information about these potential failure mechanisms.

The total work of fracture was measured at $15{ }^{\circ} \mathrm{C}$, with a rate of loading of $50 \mathrm{~mm} / \mathrm{min}$, to examine the binder performance under ductile failure conditions. The specific total 
work of fracture was obtained by dividing the total work of fracture by the crosssectional area of each ligament, Figure 16.

The examination indicates that there was a slight increase in specific total work of fracture for a cellulose fibre content of $0.5 \%$. At a cellulose fibre content of $1 \%$ the specific total work of fracture increased markedly, which may have been due to the fibres beginning to tangle together to give more reinforcement effect [2]. A $1 \%$ glass fibre content exhibits a more significant increase in specific total work of fracture, which is seven times higher than normal bitumen. This could be explained by the high tensile strength and length of glass fibre, and to the sample thickness being similar to the glass fibre length. This may cause the glass fibre to distribute into the DENT test sample in such a way that the applied load was parallel to the fibre direction, thus the tensile strength approaches that of the fibres [35]. This is in agreement with the fact that composite anisotropic materials have different material properties in all directions at any point in the structure [36]. This may be the reason why $13 \mathrm{~mm}$ glass fibre had the highest specific total work. In addition, this study could not test at $0.5 \%$ vol. glass - I fibre with $15 \mathrm{~mm}$ ligament length and $1 \%$ vol. glass $-I$ fibre with 10 and $15 \mathrm{~mm}$ ligament length, because the failure occurred in the contact area between the mould edge and bitumen before the sample fractured in the notch area (see Figure 17). This could be explained by the existence of fibre in the notch area leading to a significant increase in the tensile force required to fracture the bitumen. The SEM images (see Figure 2) are taken from DENT specimens in the notch area. Consequently, the tensile fracture force may be higher than the adhesion force between the mould and binder, and the failure happens at the mould edge instead.

The results showed that the glass-s fibre has the highest essential and plastic works of fracture, followed by cellulose fibre, as shown in Figure 18. Adding glass-s fibre leads to significant increase in bitumen toughness, which should help minimise or prevent the occurrence of longitudinal and transverse cracking in a flexible pavement. Andriescu and Hesp [34] examined the ductile failure for different bitumens in a highway paving trail. 
The tested binders were original samples taken during the construction of the test road and had been stored for several months before testing. The results showed that the pavement section with the binder with the higher toughness showed no significant cracking, while that with the binder with lower essential and plastic work of fracture exhibited alligator and longitudinal cracks. This investigation was carried out over a period of less than four years and the long-term performance may be different. However, binders with very low plastic or essential works of fracture may not perform well when used in a pavement mixture [37].

\section{Conclusions}

This paper investigated the influence of fibres on the mechanical and rheological properties of bitumen, based on penetration, softening point, viscosity, double edge notch tension and dynamic shear rheometer tests at different test temperatures. The following conclusions are offered:

- Fibre properties such as shape, size and microstructure were observed using a scanning electron microscope (SEM). These properties will influence how fibres can reinforce bitumen through the formation of three dimensional networks within the modified mastics. Glass fibre forms such a network as shown in Figure 2. These networks provide support to the mastic structure by holding the components together and spreading stresses.

- Fibres can significantly improve bitumen mastic penetration, softening point and viscosity values. Long glass fibre showed the greatest increase in terms of viscosity, softening point and decrease in penetration. This indicates an improvement in bitumen stiffness mainly at high temperatures, which is beneficial to mastic strength. High viscosity and softening point could led to reduced drain down and permanent deformation of asphalt mixture. 
- Complex modulus master curves showed that the stiffening effect of fibre additives is more significant at low frequency and high temperature, which is important to increase permanent deformation resistance of asphalt mixtures.

- Phase angle master curves showed three different patterns, but cellulose fibre exhibited different behaviour to glass fibre and led to a significant decrease in the phase angle at both high and low frequencies. This decrease in phase angle implies a significant improvement in bitumen elasticity.

- The rutting parameters increased significantly with the increase in fibre content, at moderate and high temperatures. This indicates that the addition of fibres may lead to improved rutting resistance of asphalt mixtures.

- The addition of fibre significantly improves bitumen toughness. A $1 \%$ by volume addition of short glass fibre leads to a marked increase in essential and plastic works of fracture. This is because glass fibre has high tensile strength and good adhesion with the bitumen [35]. This increase in toughness may contribute to increasing the resistance of an asphalt mixture to cracking.

List of tables

1- Table 1 Properties of fibres

2- Table 2 Experimental programme 


\section{Table 1}

Properties of fibres

\begin{tabular}{|c|c|c|c|c|c|c|}
\hline Fibre & $\begin{array}{c}\text { Specific } \\
\mathbf{d e n s i t y} \\
\mathbf{( g / \mathbf { c m } ^ { 3 } )}\end{array}$ & $\begin{array}{c}\text { Length } \\
\mathbf{( \mu \mathbf { m } )}\end{array}$ & $\begin{array}{c}\text { Widt } \\
\mathbf{h} \\
\mathbf{( \mu m )}\end{array}$ & $\begin{array}{c}\text { Modulus of } \\
\text { elasticity at } \\
\mathbf{2 3}{ }^{\circ} \mathbf{C}(\mathbf{G P a})\end{array}$ & $\begin{array}{c}\text { Absorption } \\
\text { value }\end{array}$ & Colour \\
\hline Glass-I & 2.58 & 13,000 & 12 & 80.3 & - & white \\
\hline Glass-s & 2.58 & 6,000 & 12 & 80.3 & - & white \\
\hline Cellulose & 1.50 & 20 to & 25 & - & $\begin{array}{l}\text { High } \\
\text { absorption } \\
\text { and retention } \\
\text { of liquid } \\
\text { media (water } \\
\text { binding } \\
\text { capacity) }\end{array}$ & grey \\
\hline
\end{tabular}

Table 2

Experimental programme

\begin{tabular}{|c|c|c|c|}
\hline Materials & Variables & Test methods & Test replicate \\
\hline \multirow{3}{*}{ Bitumen 40/60 } & Fibre content & Penetration test & 3 \\
\cline { 3 - 4 } & $\begin{array}{c}0.5 \% \\
1.0 \%\end{array}$ & Softening point & 2 \\
\cline { 3 - 4 } & $2.0 \%$ & Brookfield viscosity & 3 \\
\cline { 3 - 4 } Fibre & $\begin{array}{c}\text { Fibre type } \\
\text { Glass-I } \\
\text { Glass-s } \\
\text { Cellulose }\end{array}$ & Dynamic shear rheometer & 2 \\
\cline { 3 - 4 } & & Double edge notch tension test & 2 \\
\cline { 3 - 4 } & & Scanning electronic microscopy & - \\
\hline
\end{tabular}

List of figures 

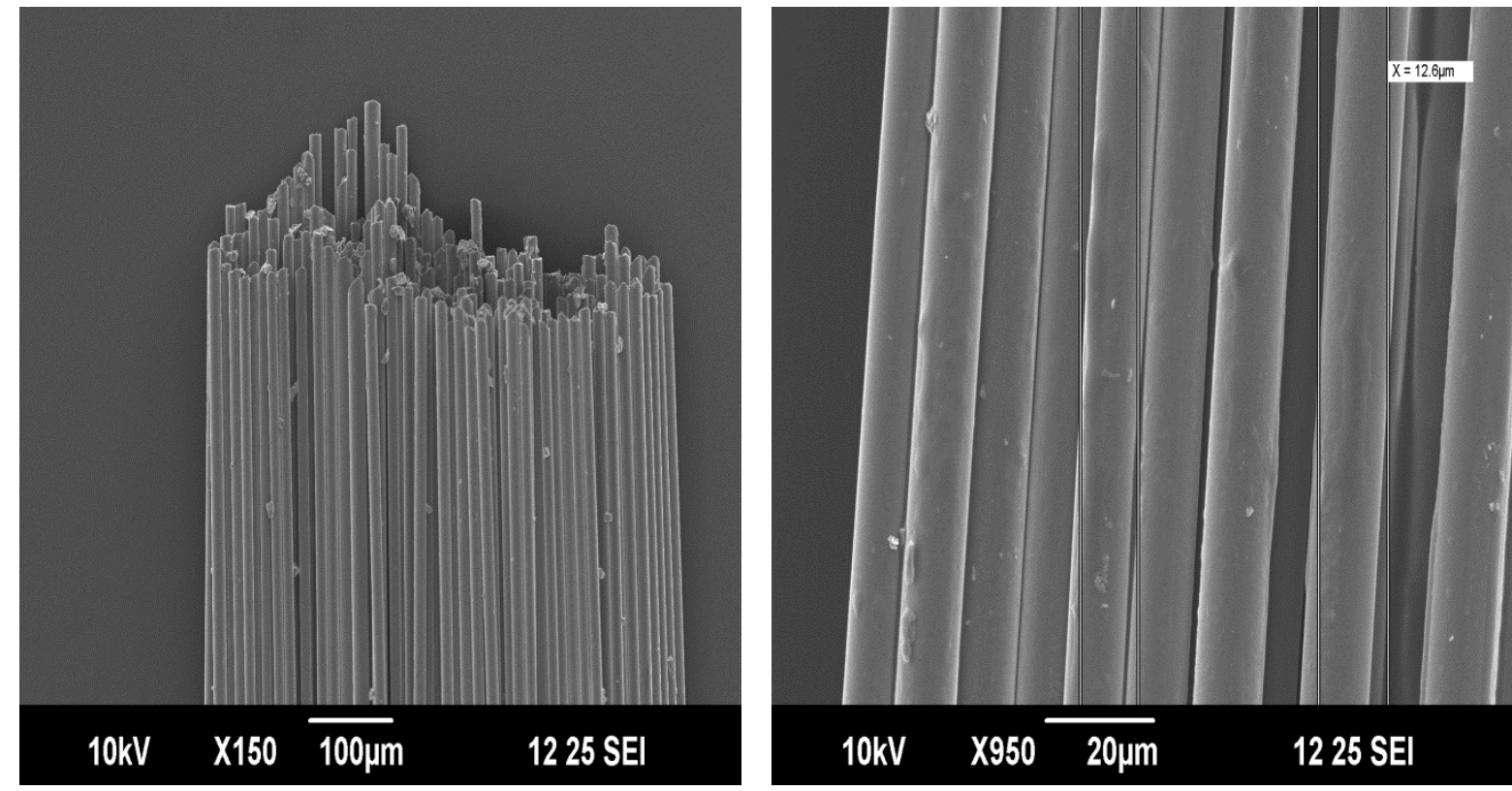

a) Glass fibre
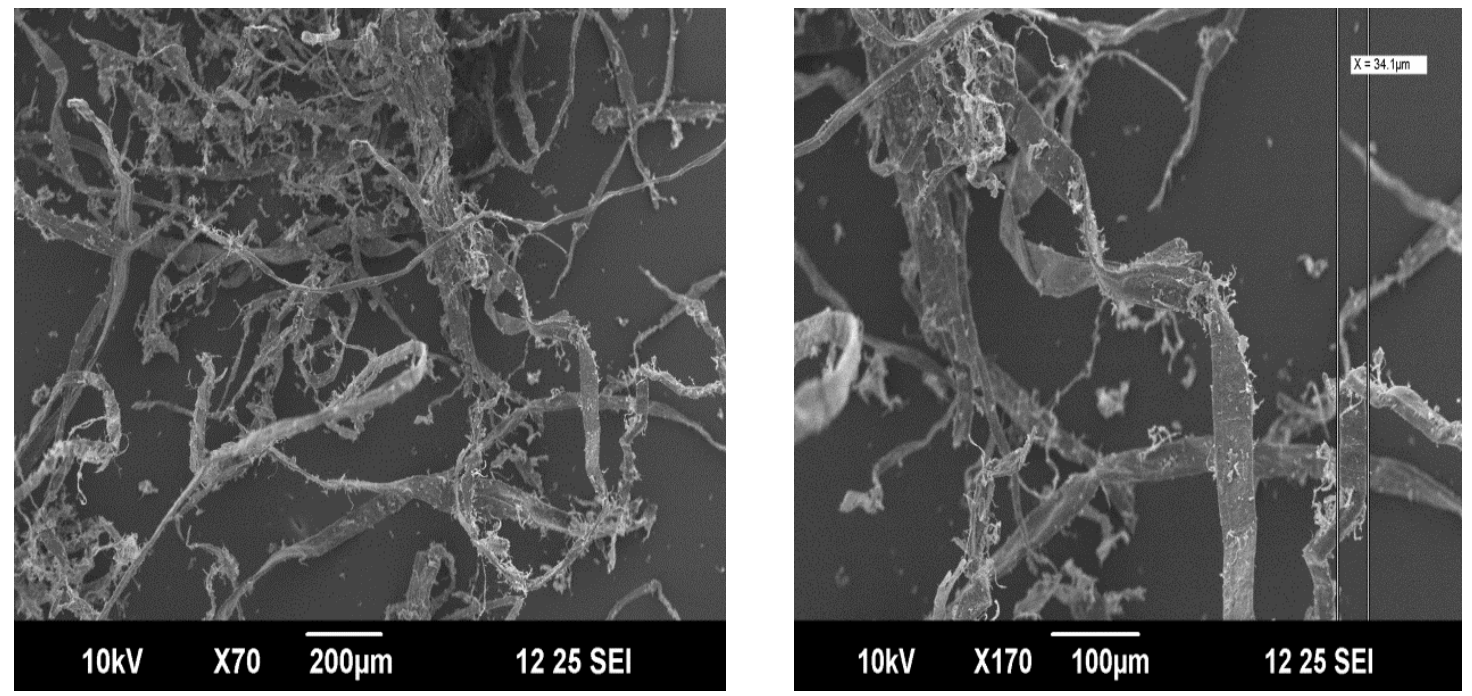

b) Cellulose fibre

Fig. 1. Scanning Electron Microscope (SEM) images of glass and cellulose fibre 

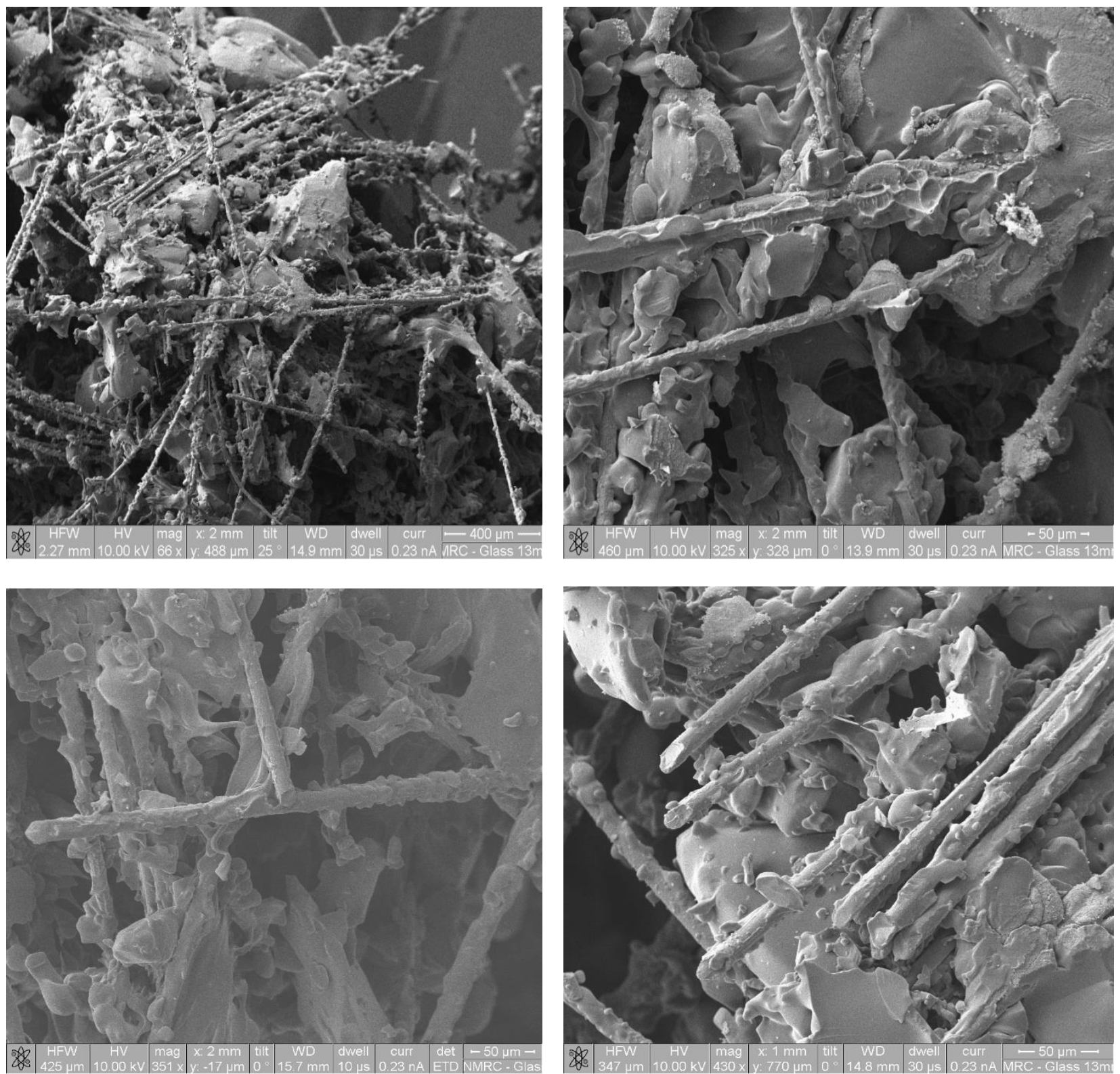

Fig. 2. Scanning Electron Microscope (SEM) images of glass fibre reinforced bitumen

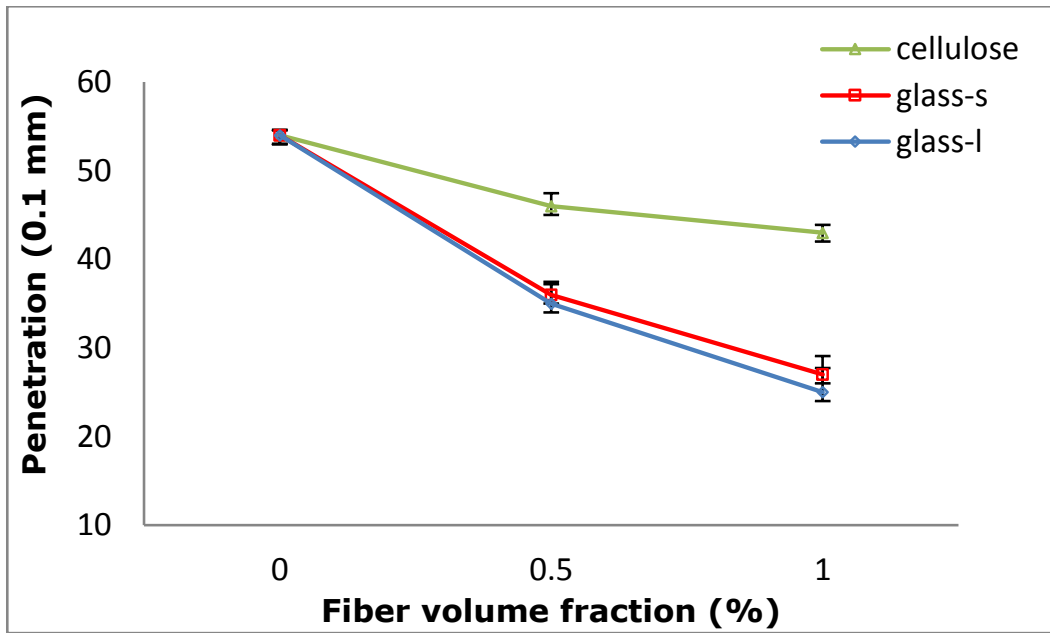

Fig. 3. Penetration of bitumen mixed with three fibre types 




Fig. 4. Softening point of bitumen mastic with three fibres

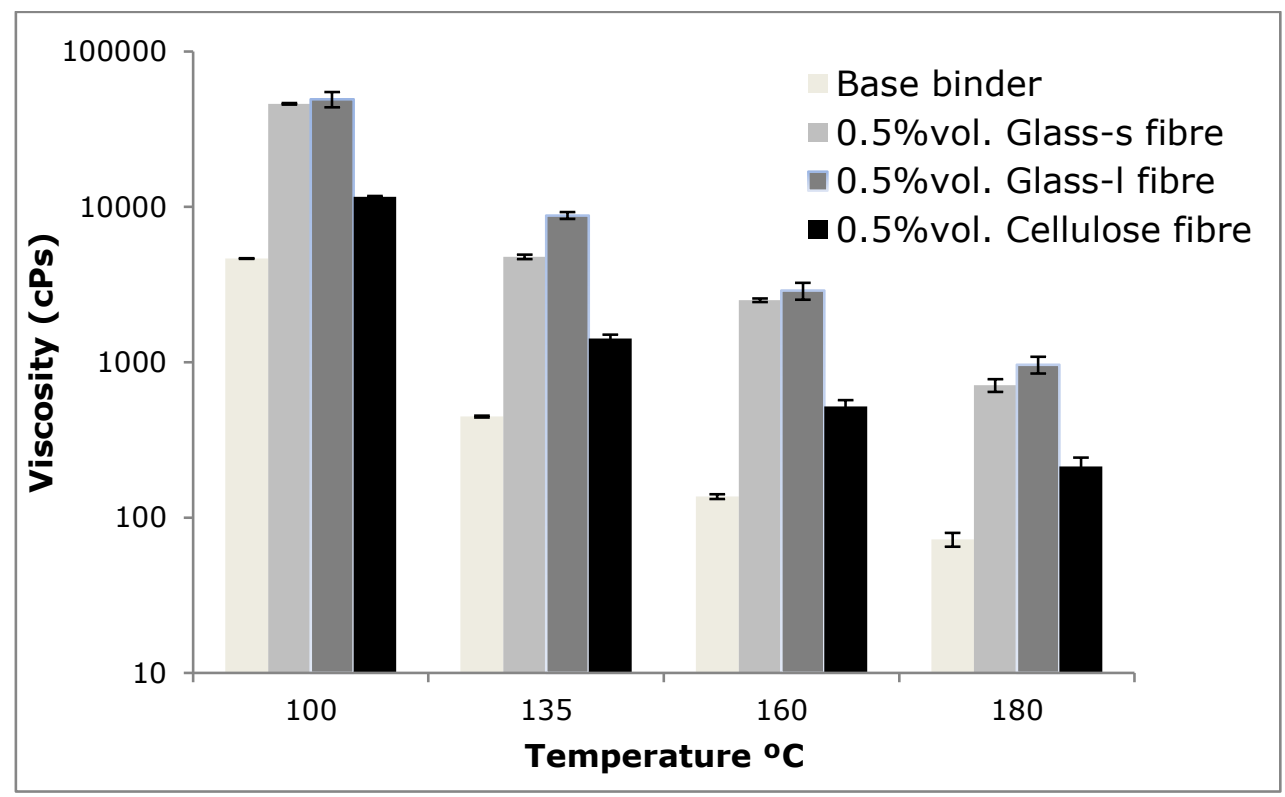

Fig. 5. Viscosity for base bitumen and $0.5 \%$ bitumen-fibre mastics 


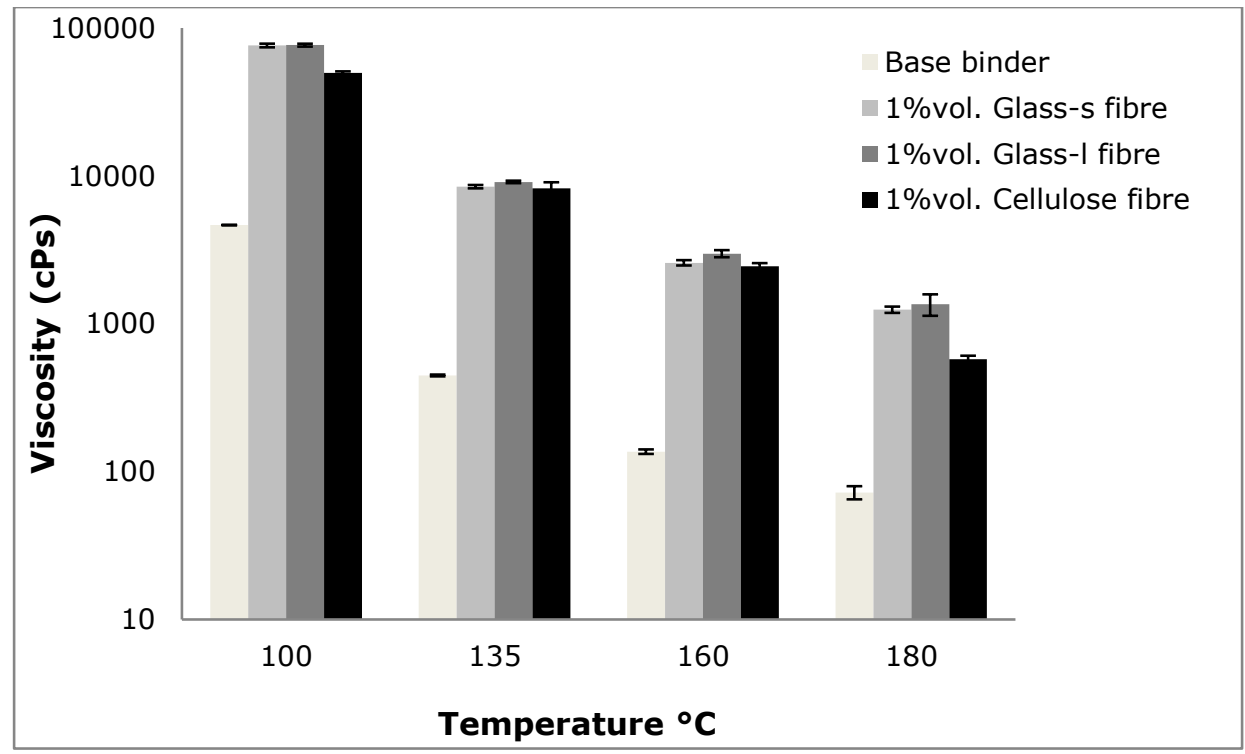

Fig. 6. Viscosity for base bitumen and $1 \%$ bitumen-fibre mastics

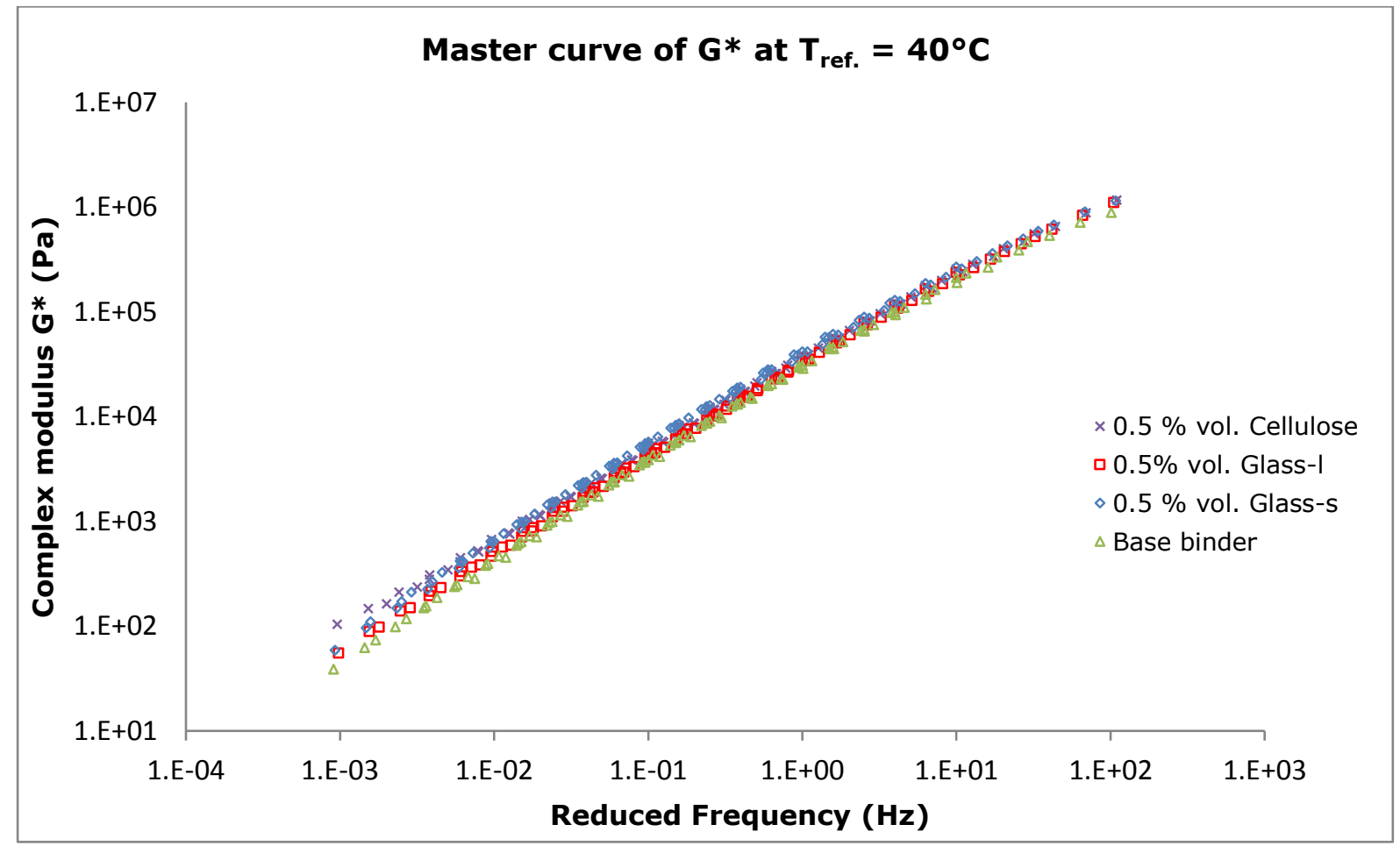

Fig. 7. Complex modulus master curves for unaged base bitumen and $0.5 \%$ bitumenfibre mastics 


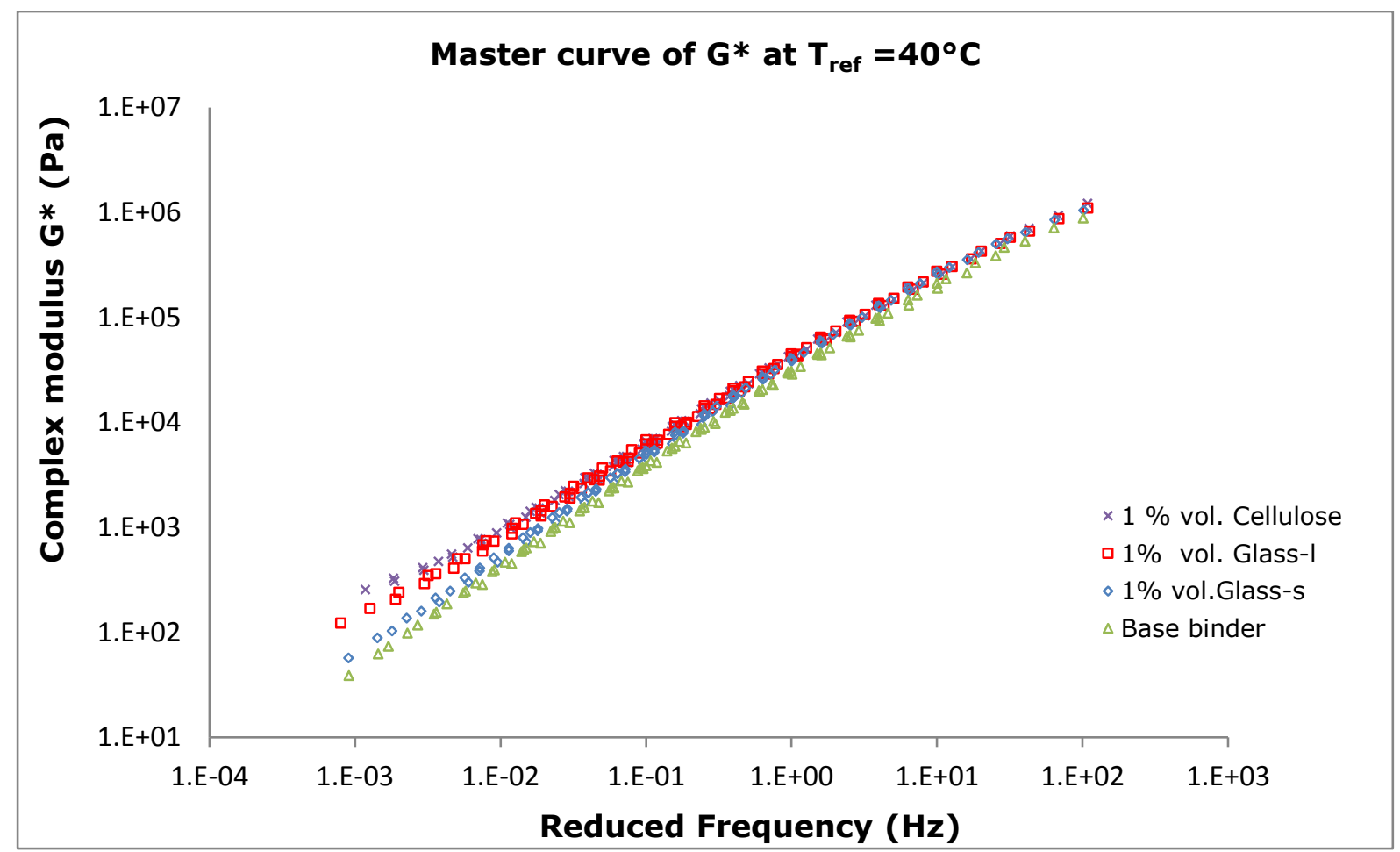

Fig. 8. Complex modulus master curves for unaged base bitumen and $1 \%$ bitumen-fibre mastics

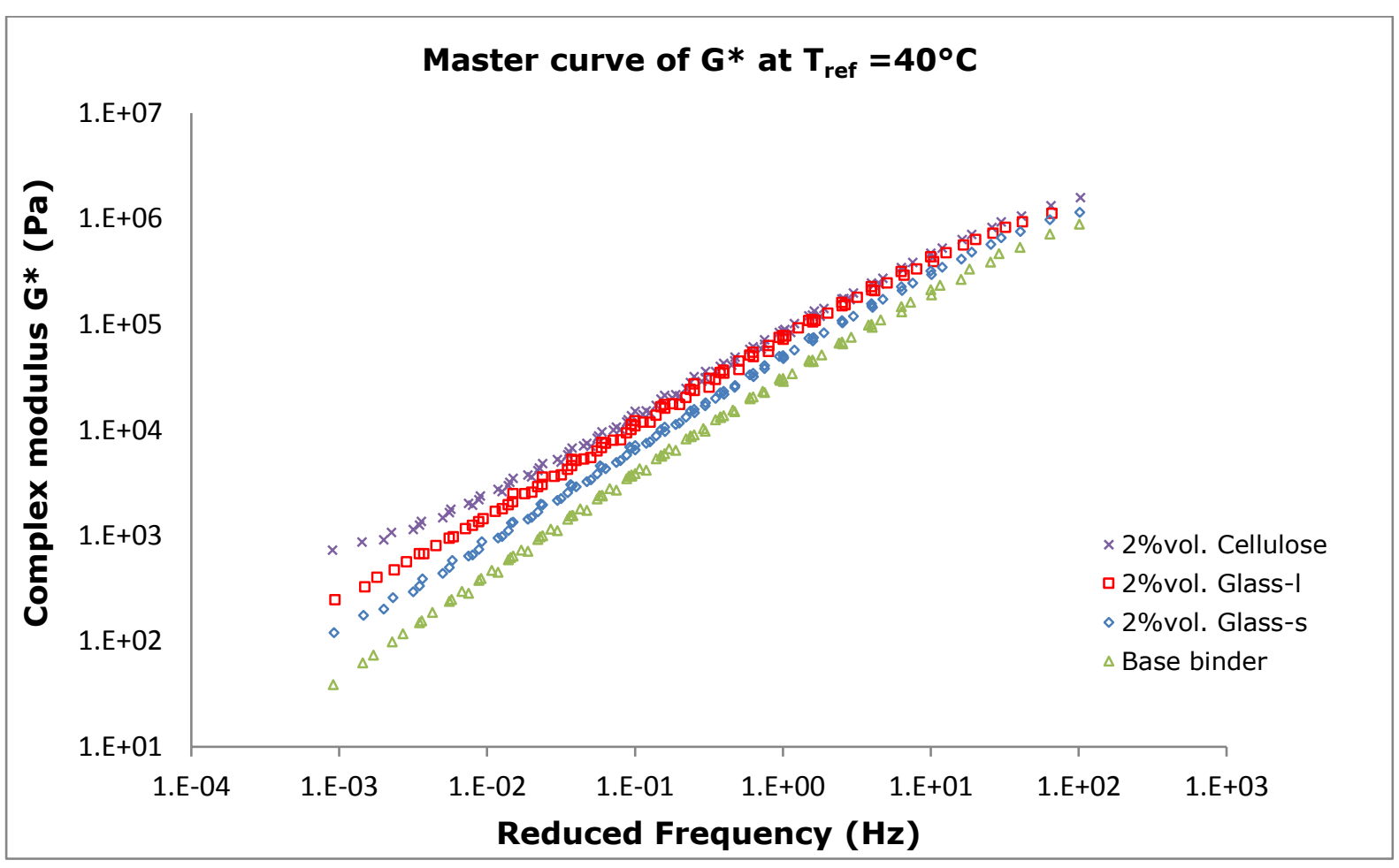

Fig. 9. Complex modulus master curves for unaged base bitumen and $2 \%$ bitumen-fibre mastics 


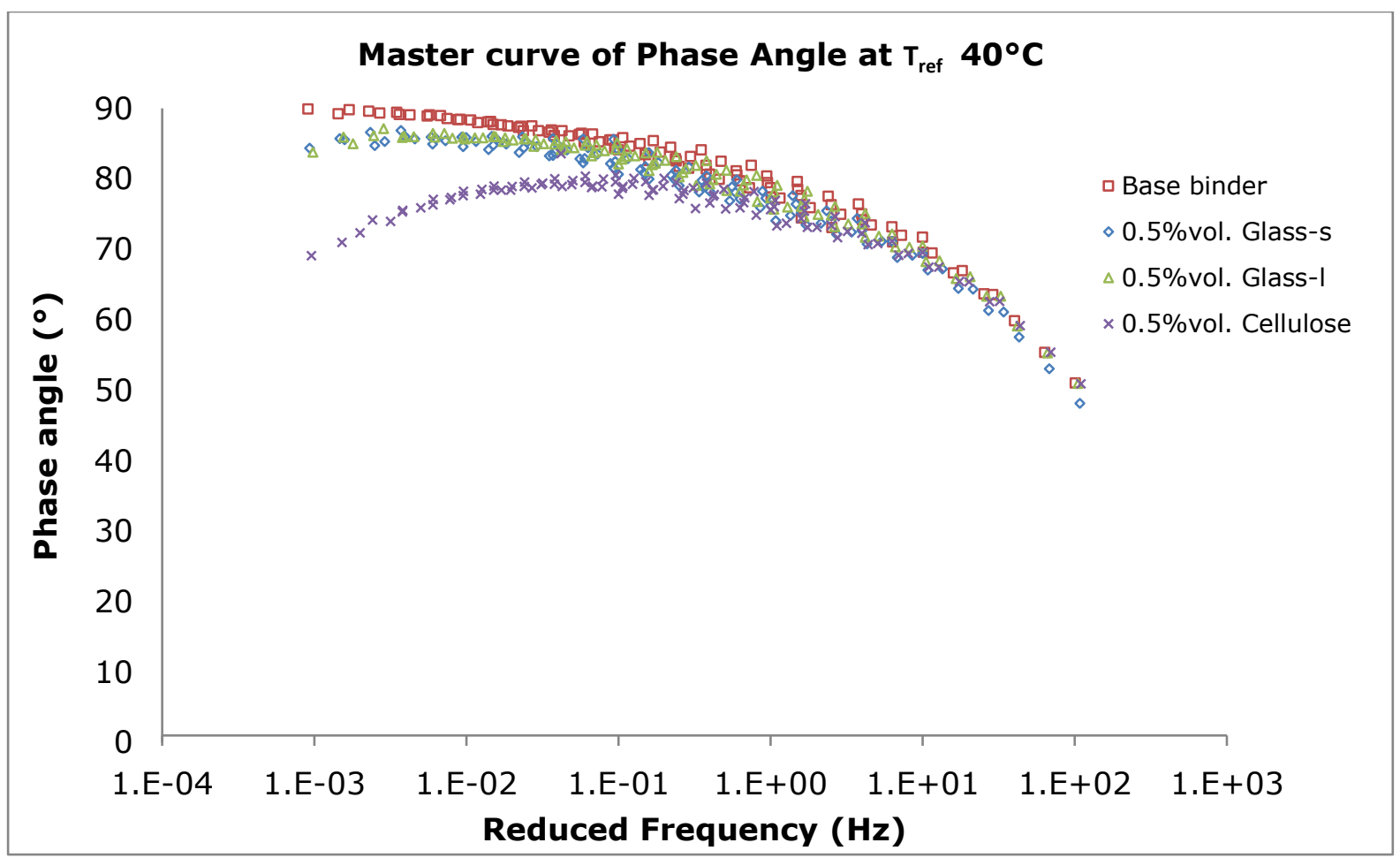

Fig. 10. Phase angle master curves for unaged base bitumen and $0.5 \%$ bitumen-fibre mastics

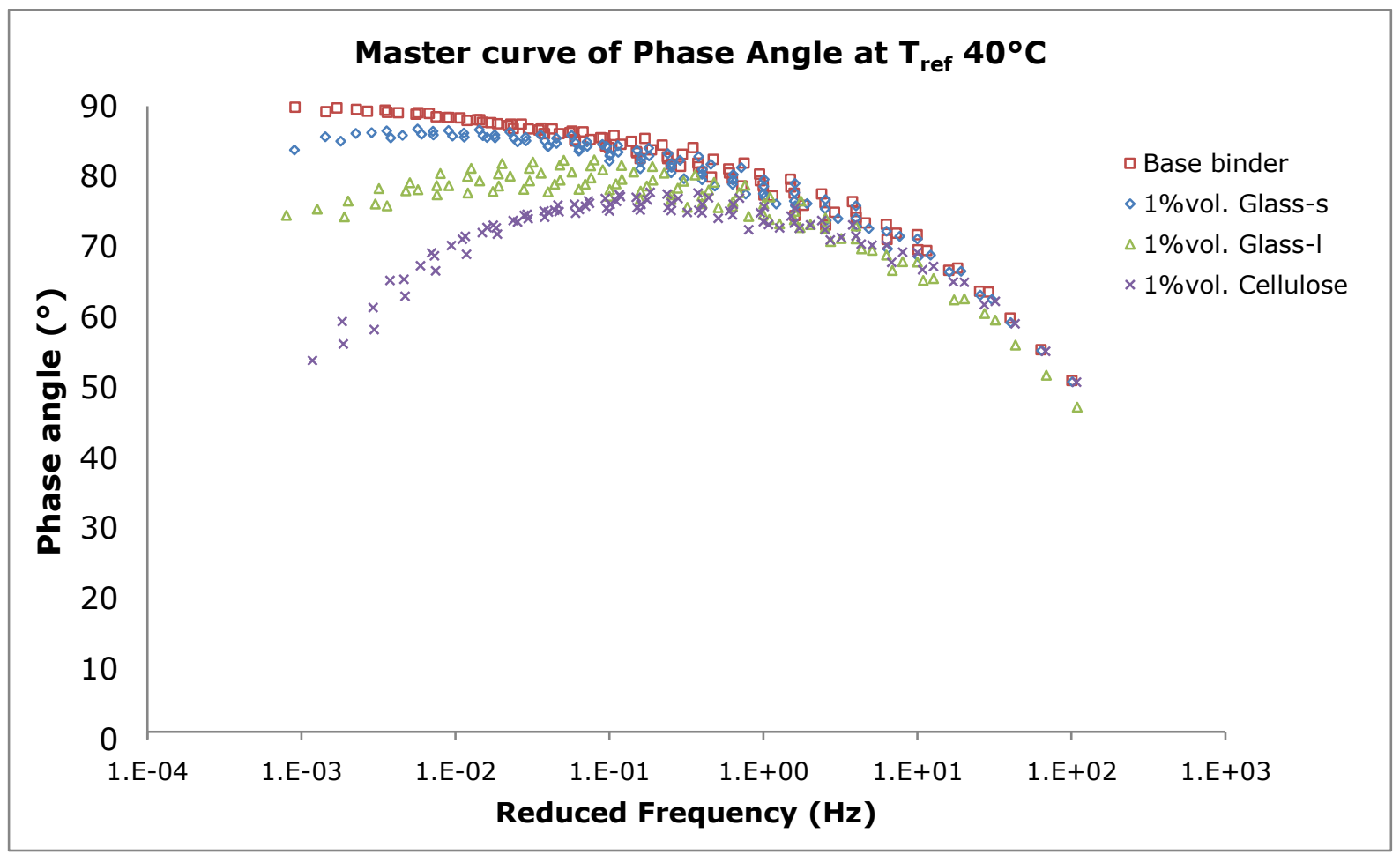

Fig. 11. Phase angle master curves for unaged base bitumen and $1 \%$ bitumen-fibre mastics 


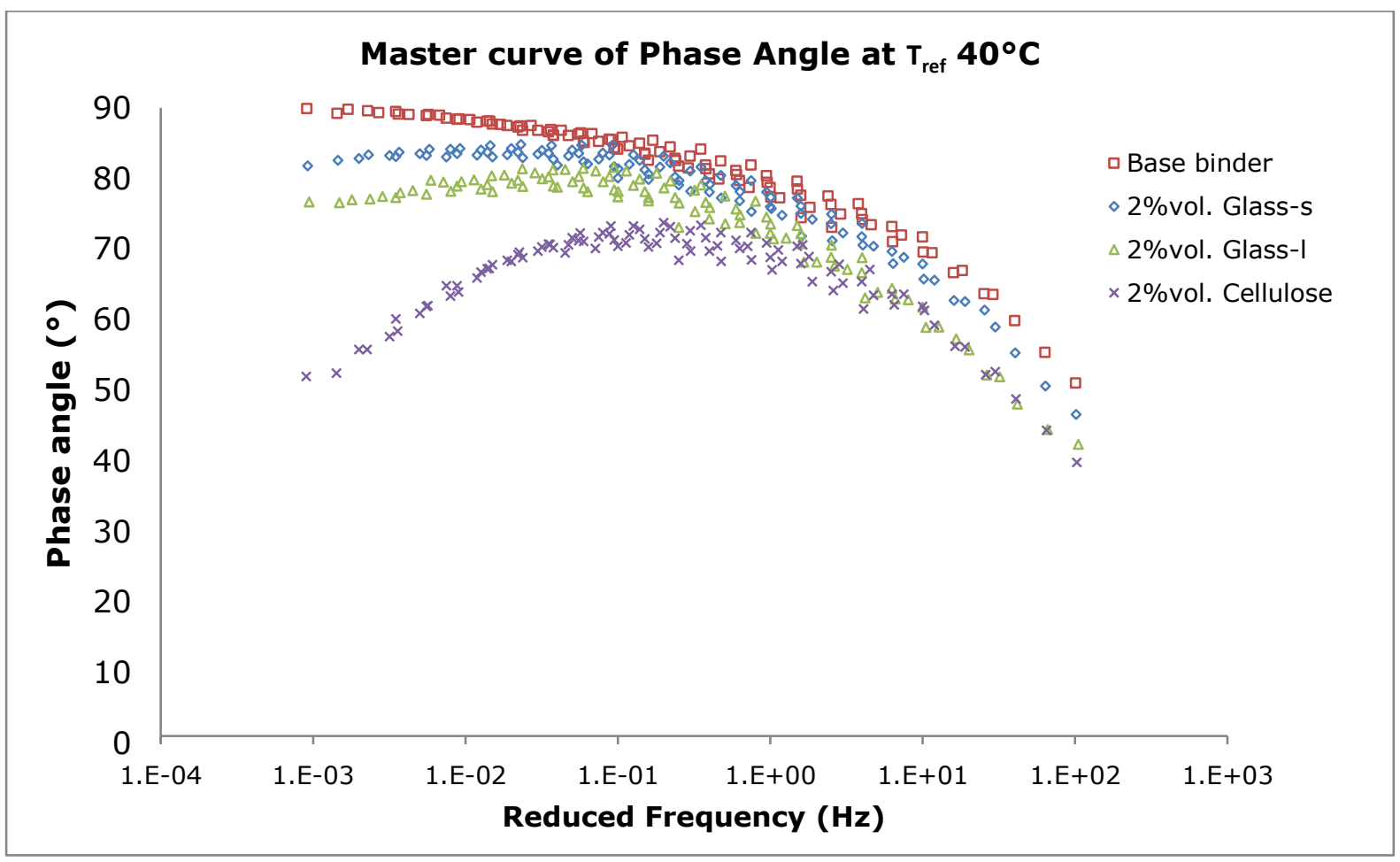

Fig. 12. Phase angle master curves for unaged base bitumen and $2 \%$ bitumen-fibre mastics

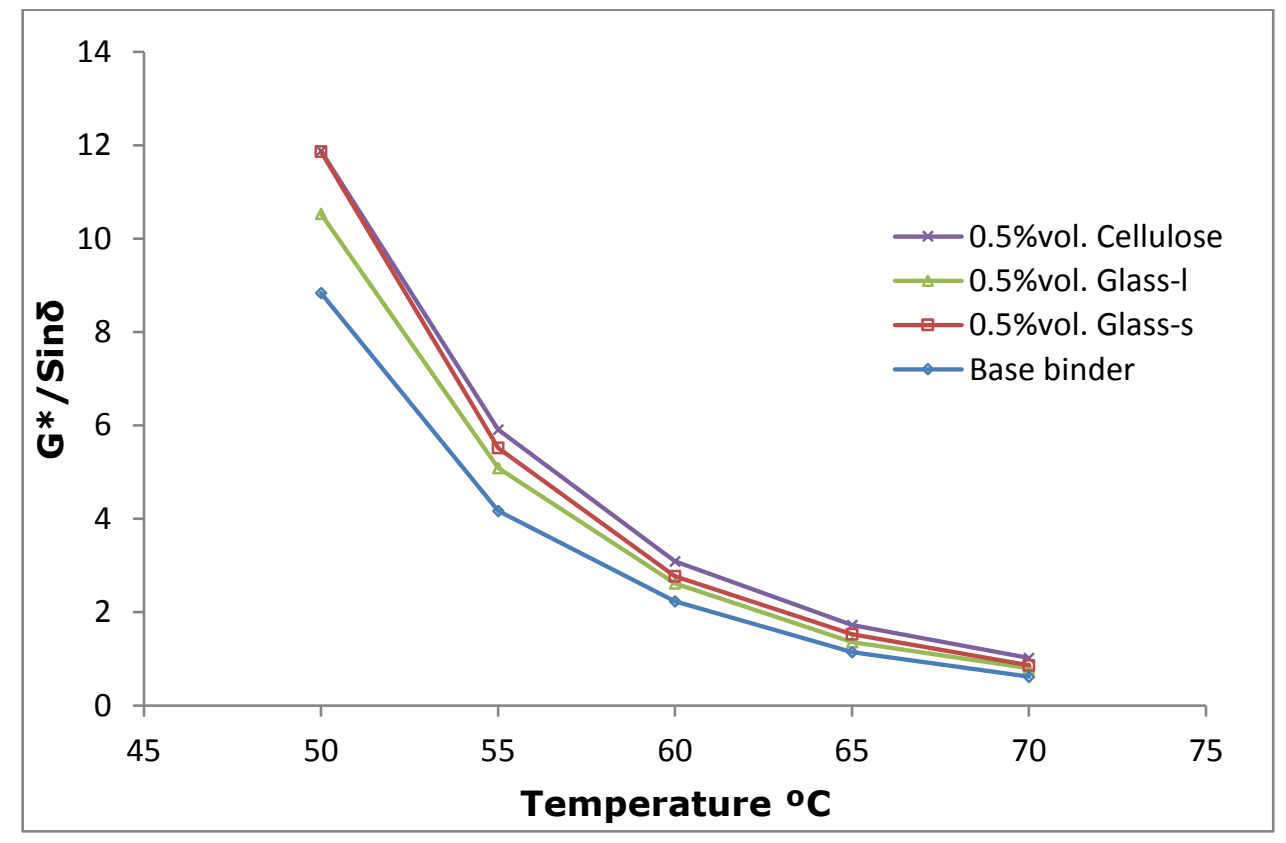

Fig. 13. Rutting parameter for unaged base bitumen and $0.5 \%$ bitumen-fibre mastics 


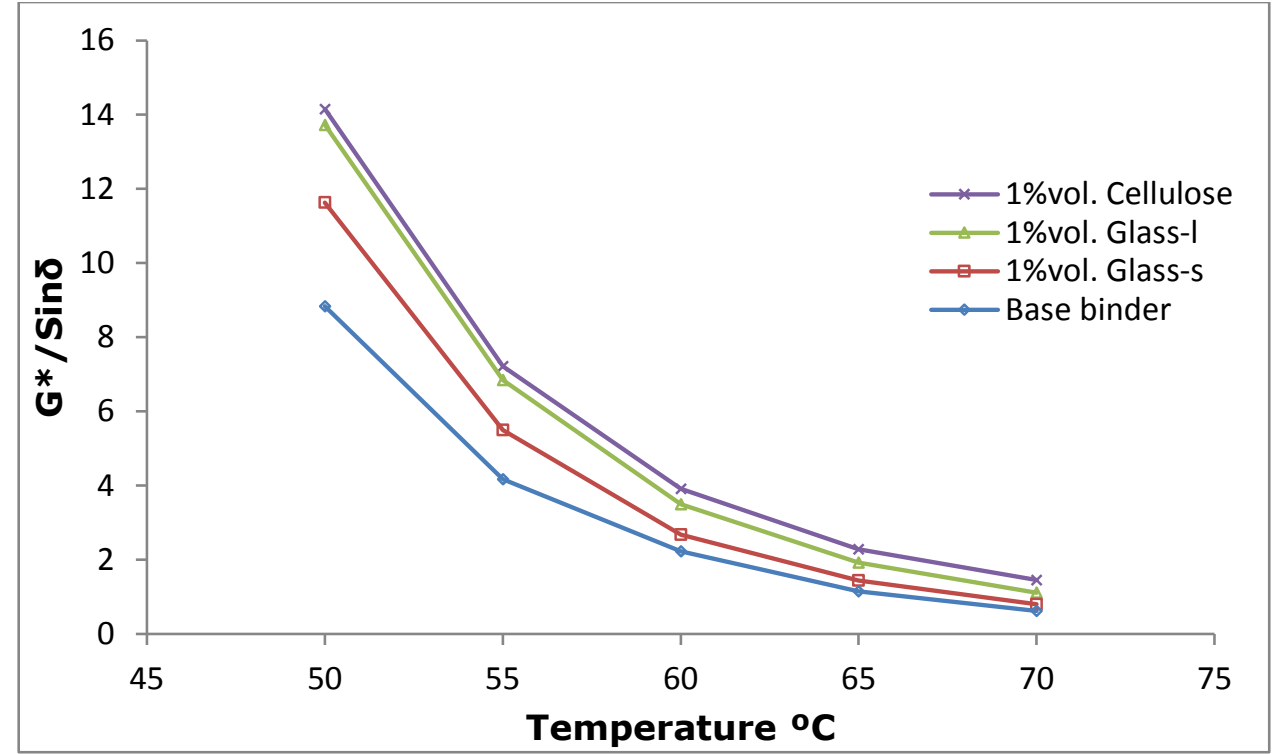

Fig. 14. Rutting parameter for unaged base bitumen and $1 \%$ bitumen-fibre mastics

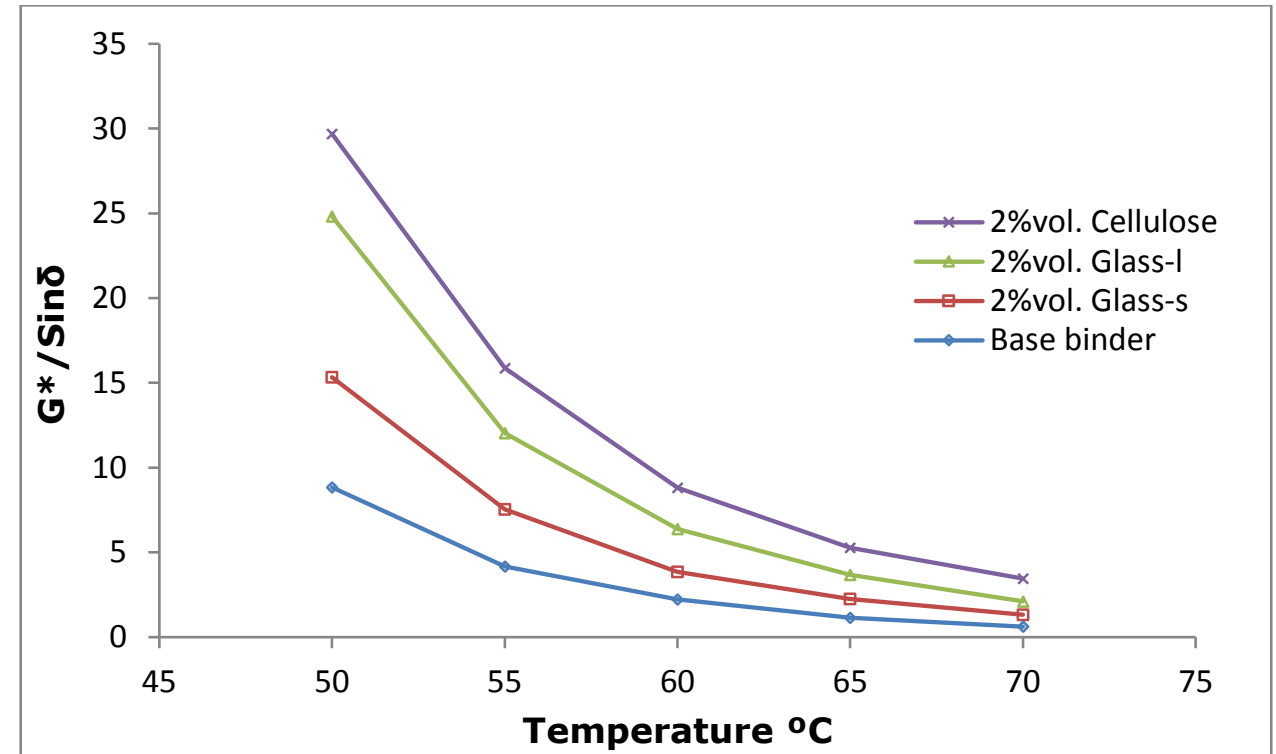

Fig. 15. Rutting parameter for unaged base bitumen and $2 \%$ bitumen-fibre mastics 


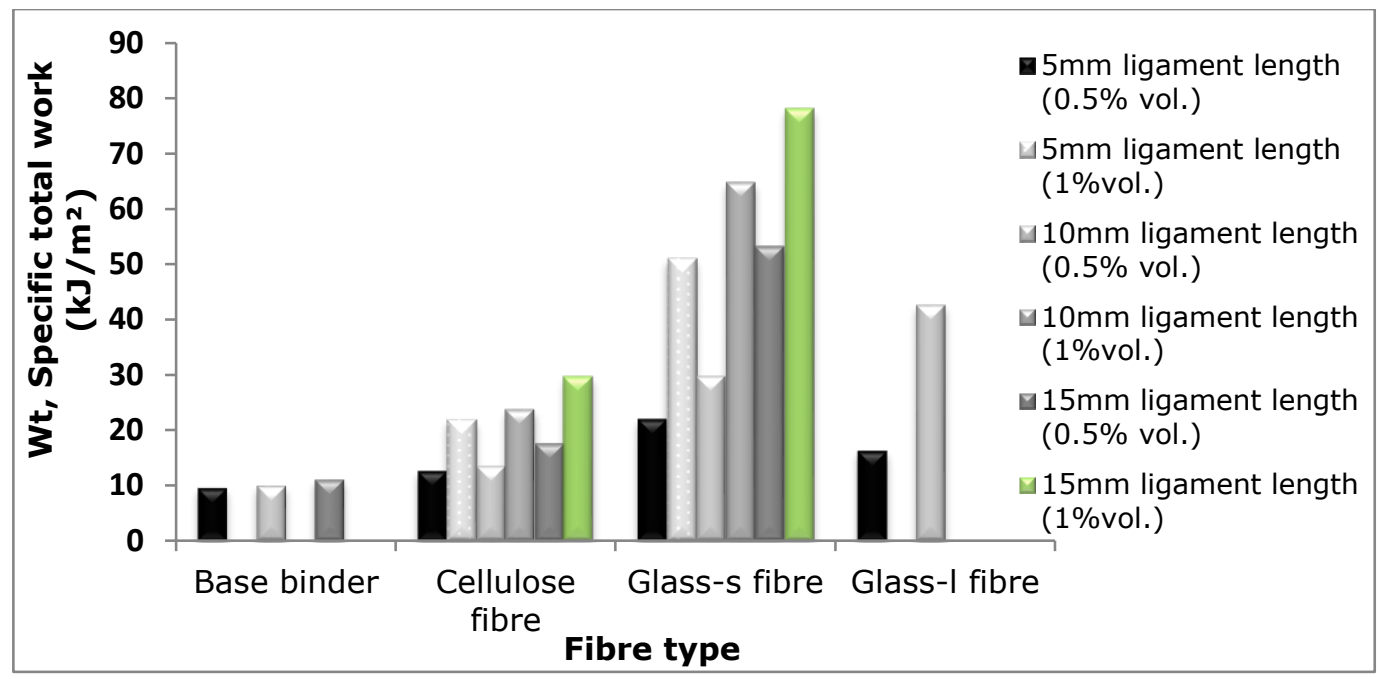

Fig. 16. Specific total work of fracture

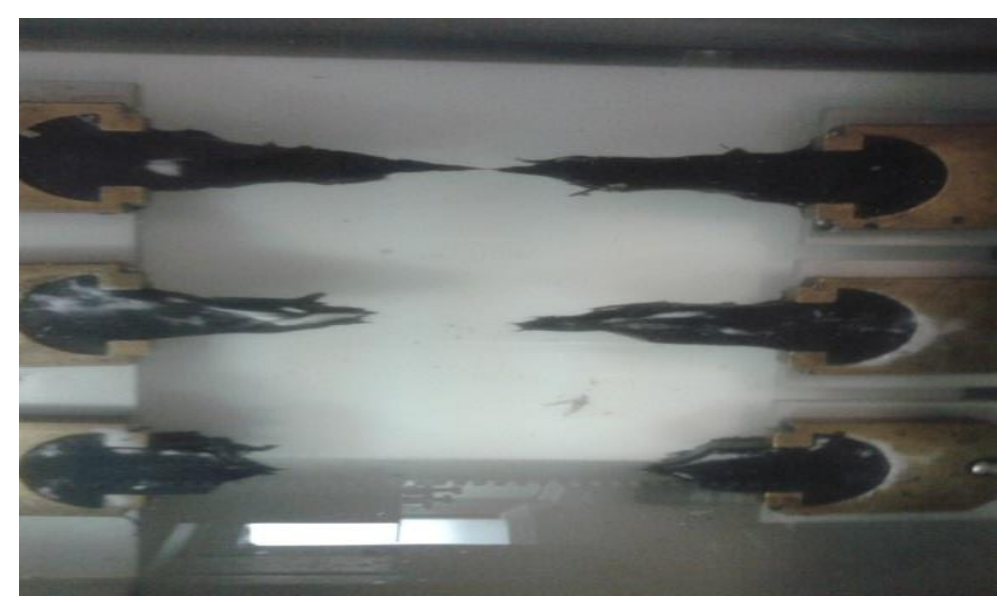

Fig. 17. DENT samples of fibre reinforced mastic after test

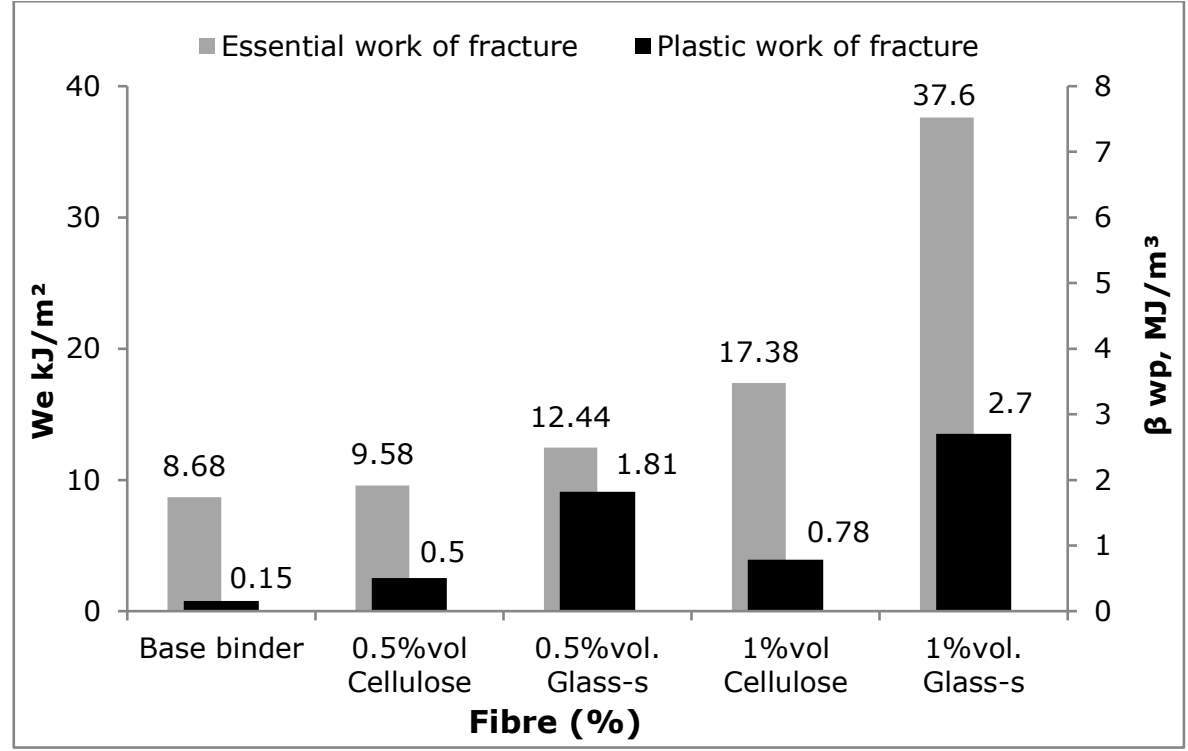

Fig. 18. Essential and plastic works of fracture 


\section{Acknowledgment}

The authors would like to acknowledge the support provided by the Nottingham Transportation Engineering Centre (NETC) at the University of Nottingham, United Kingdom. The authors acknowledge the financial support from the Higher Committee for Education Development in Iraq.

\section{References}

[1] J.-S. Chen, K.-Y. Lin, Mechanism and behavior of bitumen strength reinforcement using fibers, Journal of Materials Science 40(1) (2005) 87-95.

[2] M. Wu, R. Li, Y. Zhang, J. Wei, Y. Lv, X. Ding, Reinforcement effect of fiber and deoiled asphalt on high viscosity rubber/SBS modified asphalt mortar, Petroleum Science 11(3) (2014) 454-459.

[3] A.a.W. Sorensen, B. , Asphalt and Bitumen Ullmann's Encyclopedia of Industrial Chemistry, Hamburg 2009.

[4] S. Brown, R. Rowlett, J. Boucher, Highway research: sharing the benefits, Proceedings, The United States Strategic Highway Research Program Conference, 1990. [5] Z. Chen, S.-P. Wu, Z.-H. Zhu, J.-S. Liu, Experimental evaluation on high temperature rheological properties of various fiber modified asphalt binders., Journal of Central South University of Technology 15(1) (2008) 135-139.

[6] A.E. Alvarez, A.E. Martin, C. Estakhri, R. Izzo, Determination of volumetric properties for permeable friction course mixtures, Journal of Testing and Evaluation 37(1) (2008) $1-10$.

[7] H.F. Hassan, K.S. Al-Jabri, Effect of organic fibers on open-graded friction course mixture properties, International Journal of Pavement Engineering 6(1) (2005) 67-75.

[8] B.J. Putman, S.N. Amirkhanian, Utilization of waste fibers in stone matrix asphalt mixtures., Resources, Conservation and Recycling 42(3) (2004) 265-274.

[9] H. Zhu, J. Yang, L. Cong, J. Cui, J. Wan, Influence of polyester fibre on the performance of Asphalt mixes, Southern African Transport Conference (SATC) (2007). [10] A. Alrajhi, Fiber dosage effects in asphalt binders and hot mix asphalt mixtures., Civil and Environmental Engineering Arizona State University, Civil and Environmental Engineering 2012.

[11] B. Guan, R. Xiong, R. He, S.-F. Chen, D.-H. Ding, Investigation of usability of brucite fber in asphalt mixture., International Journal of Pavement Research and Technology 7(3) (2014) 193-202.

[12] X. Yu, L. Sun, Anti-cracking ability of asphalt mixture added with polyester fiber., Traffic and Transportation Studies 2010, ASCE, 2010, pp. 1399-1406.

[13] H.-X. Chen, N.-L. Li, C.-S. Hu, Z. Zhang, Mechanical performance of fibersreinforced asphalt mixture, Journal of Chang'an University (Natural Science Edition) 24(2) (2004) 1-5.

[14] S.M. Abtahi, S. Esfandiarpour, M. Kunt, S.M. Hejazi, M.G. Ebrahimi, Hybrid reinforcement of asphalt-concrete mixtures using glass and polypropylene fibers, Journal of Engineered Fibers and Fabrics 8(2) (2013) 25-35.

[15] European Committee and British Standardad, 1426: Bitumen and bituminous binders-determination of needle penetration, British Standards (2007).

[16] European Committee and British Standard, Bitumen and bituminous bindersDetermination of the softening point-Ring and Ball method, BSI Standards Publication, 2015.

[17] Europen Commoittee and British Standard, Bitumen and bituminous bindersdetermination of dynamic viscosity of bituminous binder using rotating spindle apparatus, British Standards, 2010. 
[18] G.D. Airey, Rheological characteristics of polymer modified and aged bitumens, University of Nottingham, 1997.

[19] LS-299, Method of Test for The Determination of Asphalt Cement's Resistance to Ductile Failure Using Double Edge Notched Tension Test (DENT), Ministry of Transportation of Ontario Laboratory Testing Manual (2001).

[20] J.D. Ferry, Viscoelastic properties of polymers, John Wiley \& Sons 1980.

[21] S. Bagherpour, Fibre reinforced polyester composites, Edited by Hosam El-Din M. Saleh (2012) 167.

[22] T. Mezger, The Rheology Handbook. 2011. 3-rd Revised Edition, Hanover, Germany 436.

[23] W. Shaopeng, C. Zheng, Y. Qunshan, L. Weidong, Effects of fibre additive on the high temperature property of asphalt binder, Journal of Wuhan University of TechnologyMater. Sci. Ed. 21(1) (2006) 118-120.

[24] Y.B. Ab-Wahab, Development of the simplified method to evaluate dynamic mechanical analysis data on asphalt-aggregate mixtures., Dpartment of Civil Engineering, Oregon State University., 1993.

[25] B.J. Putman, S.N. Amirkhanian, Utilization of waste fibers in stone matrix asphalt mixtures, Resources, conservation and recycling 42(3) (2004) 265-274.

[26] G.D. Airey, Rheological properties of styrene butadiene styrene polymer modified road bitumens, Fuel 82(14) (2003) 1709-1719.

[27] X. Lu, U. Isacsson, Compatibility and storage stability of styrene-butadiene-styrene copolymer modified bitumens, Materials and Structures 30(10) (1997) 618-626.

[28] L. Socal da Silva, M.M. de Camargo Forte, L. de Alencastro Vignol, N.S.M. Cardozo, Study of rheological properties of pure and polymer-modified Brazilian asphalt binders, Journal of materials science 39(2) (2004) 539-546.

[29] S.M. Asgharzadeh, N. Tabatabaee, K. Naderi, M.N. Partl, Evaluation of rheological master curve models for bituminous binders, Materials and Structures 48(1-2) (2015) 393-406.

[30] G.L. Baumgardner, J. Masson, J.R. Hardee, A.M. Menapace, A.G. Williams, Polyphosphoric acid modified asphalt: proposed mechanisms, Journal of the Association of Asphalt Paving Technologists 74 (2005) 283-305.

[31] P. De Filippis, C. Giavarini, M. Scarsella, Improving the ageing resistance of straight-run bitumens by addition of phosphorus compounds, Fuel 74(6) (1995) 836 841.

[32] R.A. Al-Mansob, A. Ismail, A.N. Alduri, C.H. Azhari, M.R. Karim, N.I.M. Yusoff, Physical and rheological properties of epoxidized natural rubber modified bitumens, Construction and Building Materials 63 (2014) 242-248.

[33] A. Ragab, R.K. Farag, U.F. Kandil, M. El-Shafie, A. Saleh, A.F. El-Kafrawy, Thermomechanical properties improvement of asphalt binder by using methylmethacrylate/ethylene glycol dimethacrylate, Egyptian Journal of Petroleum 25(3) (2016) 397-407.

[34] A. Andriescu, S.A. Hesp, Time-temperature superposition in rheology and ductile failure of asphalt binders, International Journal of Pavement Engineering 10(4) (2009) 229-240.

[35] F.L. Matthews, R.D. Rawlings, Composite materials: engineering and science, Elsevier1999.

[36] F.C. Campbell, Structural composite materials, ASM international2010.

[37] A. Andriescu, S. Hesp, J. Youtcheff, Essential and plastic works of ductile fracture in asphalt binders, Transportation Research Record: Journal of the Transportation Research Board (1875) (2004) 1-7. 